\title{
On Paradoxes and Antinomies in the Human Thinking
}

\section{Olkhovsky vs ${ }^{1^{*}}$}

Institute for Nuclear Research of NASU, Kiev, Ukraine

"Corresponding author: Olkhovsky VS, Institute for Nuclear Research of NASU, Kiev-028, Ukraine, Tel: 38044525835; E-mail: olkhovsky@mail.ru Rec date: Jan 31, 2014; Acc date: Apr 28, 2014; Pub date: May 02, 2014

Copyright: (c) 2014 Olkhovsky VS. This is an open-access article distributed under the terms of the Creative Commons Attribution License, which permits unrestricted use, distribution, and reproduction in any medium, provided the original author and source are credited.

\section{Summary}

Here there are represented the definitions of the conceptions paradox and antinomy and also some accompanying conceptions. The well-known paradox of liar, which had not its solution during many centuries, is considered. Antinomies of Kant I and Ushinsky K are analyzed. Briefly the consequences of the Goedel theorem, paradoxes of quantum mechanics and some Bible antinomies are formulated. In conclusion there are discussed the significance and use of paradoxes in science and theology.

\section{Introduction}

From the antiquity the representatives of the rational thinking in philosophy and then in science and theology had observed the existence of paradoxes and antinomies in the human thinking as an inevitable reality. Here their definitions and the definitions of some accompanying conceptions are considered. Then some antinomies, introduced by German philosopher I Kant and Russian pedagogue KD Ushinsky, are examined [1]. Briefly the consequences of the Goedel theorem, paradoxes of quantum mechanics and some Bible antinomies are formulated. In conclusion there are discussed the significance and advantage of paradoxes in science and theology.

\section{Definitions of Paradox and Antinomy}

In the wide sense paradox is the statement which differs sharply with the generally accepted, well-established orthodox opinions. Any paradox is in its essence the start of an investigation. In the narrow sense the strict paradox is the union of two self-contradictory statements, in favor of which there are the convincing arguments.

It is useful to compare paradox and sophism. In usual and diffused comprehension sophism is the intentional deception, based on the violation of rules in language and logics (often on the hidden or evident contradiction). Usually such deceit is fine and veiled - and not always everyone can reveal it. The aim of sophism is to present the falsity as a truth. To sophism as an intentional mistake one can oppose paralogism which is understand as an intentional mistake, conditioned by the violation of laws and rules of logics.

In its essence, sophism is imaginary problem, because it is an external obstacle on the way of carried on discussion. An example of an old sophism: What do not you lose, you have; the corns you did not lose, so you have the corns.

However, the bound between sophisms and paradoxes is not clearly defined: sometimes it is impossible on the base of the standard versions of their definitions to decide to which of them one can refer the given statement. In particular, there are known the well-known historical examples "Protagoras and Evatlos", "Akhilles and tortoise".
The mostly sharp form of paradox is antinomy, i.e. the statement, which proves the equivalence of two statements, one of which is a negation of another one.

The particularly known are the paradoxes in the mostly strict and exact sciences - mathematics, logics and from XXc. also in the theoretical physics. Clearly formulated paradoxes are the important bases in the elaborations of the logical theory. Paradoxes for logics (as a theory) are similar to the experiments in the natural sciences. Paradoxes and antinomies are often used in the Bible. Jesus Christ had often used paradoxes in his parables.

One of easily solved paradoxes is "a man can be father and son simultaneously" (only in the same relation nobody can be his own father). The re of logical paradoxes is the paradox of liar: That I say now is lie. The truth or the lie I have said?"

Here is the essence of one of its versions:

If the statement is true and the saying person claims that it is false, then it is false [i.e. if I said the truth, then I said the lie]

If the statement is false, then the saying person claims that it is truth, then it is not false [i.e. if I said the lie, then I said the truth]

From 1 and $2 \rightarrow$ it follows that the truth is identical to the lie [i.e. if the saying person lies, then he says the true, and vice versa]

About it is said in the letter of Paul to Titus $(1,12)$ : One of themselves, even a prophet of their own, said, The Cre'tians are always liars". Let remind briefly the reasoning of Eubulides:

A Cre'tian said that all Cre'tians are liars.

If he is a liar, then he is a liar himself.

But if he is a liar, then his statement is false - hence The Cre'tians are not liars -

\section{And he himself is not a liar.}

Then his statement, that all Cre'tians are liars, is false!

To this paradox was dedicated the vast scientific literature and till recently it was considered to be without solution at all. Only recently it began to be considered as an example of those difficulties, to which the confusion of two languages brings: the language, by which the people say about the reality outside of this language (objective language), and the language, by which the people say about the first language itself (meta-language). In everyday language there is no distinction between these levels (for instance, there is no difference in expressions "glass is transparent" (about the glass itself) and "it is true that glass is transparent" (about statement relative the glass). And if someone wishes to say about world by one language, and about the properties of this language by another language, he could use two different languages (for instance, Russian and English). The distinction of 
Page 2 of 3

language and meta-language permits to eliminate the paradox of liar (at least, formally).

\section{Antinomies of Kant and Ushinsky}

I Kant defined antinomies as the manifestations of the mind conflict with itself, in which the contradictory statements - "thesis" and "antithesis"- equally convincing for mind.

\section{Thesis}

The world has beginning in time and has the limits in space.

Everything in the world is simple or elements.

In the world the freedom exists.

\section{Antithesis}

The world has no beginning in time and has no limits in space.

Nothing in the world is simple or consists of simple consists from simple elements.

In the world there is no freedom and everything takes place only by the nature laws.
Trying to solve these difficulties, mind (intellect) is confused (tangled): finiteness-infinity, divisibility-indivisibility, causalityfreedom, case-necessity are the eternal problems. Moreover, cosmologic antinomies, formulated by Kant, were interpreted so widely that they are embraced namely all metaphysics, the first relates also to the theology, the second and third relate to psychology.

Can they be solved? Their solution is impossible, if someone assume that the truth is either thesis, or antithesis. But Kant could solve them: for him the first two antinomies neither thesis, nor antithesis was not the truth, and the third antinomy either thesis, or antithesis was true,His solution he based on the distinction of the world of events and the world of thoughts. Since for him space and time are not real objects but only subjective forms of mastering the object, then first two antinomies become pointless. The third (etc) antinomy was solved by him in another way. The same fact can be conditioned and free simultaneously in the world of events where the causality principle acts and out of the world of events the causality principle is not valid. So Kant solve third (etc) antinomy on another way: thesis is true in the world of thought, antithesis is true in the world of events.

Hegel went much more farther than Kant: for Hegel the contradiction is always real because it is a source of any motion, development,

KD Ushinsky [1] in his the theoretical works on pedagogue had discussed 2 antinomies in human thinking (conscience):

- Causality and will freedom,

- Dualism and monism in relation with human view-world, considering also personal internal world

He finally stated that [2] from the first side, a human being feels the existence of two worlds inside himself (material and spiritual), and from the second side, the human conscience tends to unity; [3] monism and causality are usually in the base of the natural sciences, and dualism and will freedom are in the base of any practical activity and human education.

\section{On the Goedel Theorem}

In logics of XXc. the principal limitations on the consistency of the following conclusions which posed, for instance, in arithmetic logics by the Goedel theorem. Let remind the main conclusions of the Goedel theorem:

The impossibility of meta-mathematic proof of the consistency of arithmetic logics (and moreover, of a more wide system, including it) by those methods which are expressible in this logics.

Any adequate self-consistent arithmetic logics is incomplete, i.e. for any given self-consistent system of the arithmetic axioms one can find true arithmetic statements which are irreducible from the axioms of this system (moreover, it takes place for any more wide system, including it).

\section{Problems-paradoxes of Quantum Mechanics}

Revolution in physics in the beginning of 20-th c. together with its legendary successes brought to the appearing of new problems paradoxes in physics and, moreover, came out of the limits the old physics, bringing to the reconsideration (different interpretation) of the old trends and origin of the new trends of philosophy and Christian theology, connected with the deepening of the understanding of the paradox and antinomy role in the human thinking.

Those circumstance that on the microscopic level there is irremovable indeterminism, according to which there is taking place the probabilistic distribution of the measurable quantities and it is impossible to foresee, as a rule, the result of the single experiment, did a challenge appear for philosophy and till now originates the discussions for physicists and philosophers. Such an indeterminism is also represented by the Heisenberg uncertainty relations for mechanical characteristics of micro-particles and by the nonlocalizability of still non-measured particles-waves. And at the same time in quantum mechanics it is used the special quantity (the so called wave function) for the calculation of the measurement results. And this quantity is described in a deterministic way, i.e. the change of the probability in time is described mathematically exactly and in a univalent way.

One of the most important contributions of A Einstein and N Bohr in the result of their long discussion in the physics of the 20-th c. were: the description of the events and objects with the help of the mutually exclusive conceptions on quantum physics (for instance, the description of the conceits particle and wave for the same micro-object in different experimental conditions, dualism indeterminismdeterminism), the introduction of the complementarity principle (which signifies that 2 or more different considerations can describe something by the joint application out of the possibilities of every consideration separately), and also the extension and deepening of the paradox method not only in theoretical physics, but in all culture of the human thinking.

Till now it is widely discussing and already applied in quantum physics and quantum informatics the Einstein-Podolsky-Rosen paradox. It consists of the simultaneous manifestation of locality and un-locality: equations of quantum theory are local but at the same time the result of the measurement for one part of the quantum microsystem, consisting of two entangled parts, instantaneously influenced 
Page 3 of 3

(namely in this the un-locality is manifested) on the result of measurement of another part of this micro-system independently from the distance of the removal of both parts.

Problems and paradoxes of quantum theory did seriously undermine the traditional forms of the naïve realism and strongly influenced also our understanding of the human knowledge at all.

\section{The Biblical Antinomies}

The term supplementarity principle from quantum mechanics was transferred by some protestant theologians of $20 \mathrm{c}$. in the Christian theology for the supplementary description interrelation between science and theology in the cognition of the reality in the framework of one integral picture (or system). And method of the paradoxical thinking brought to the development of antinomy theology by the orthodox Christians of $20 \mathrm{c}$. and paradoxical (or also antinomy) theology by the protestant theologians of $20 \mathrm{c}$., when it was cleared up that to both reality and Bible refer both thesis and antithesis.

One can show to some biblical antinomies:

- Absolute sovranitá of God $\leftrightarrow$ the human responsibility.

- Personal tri-unity (unity $\leftrightarrow$ in three persons) of God.

- Jesus Christ as God $\leftrightarrow$ man.

- Two natures in a Christian: "old man" and "new man"

[as to two natures see (Ephes., 4:22-24): That ye put off concerning the former conversation the old man, which is corrupt according to the deceitful lusts; And he renewed in the spirit of your mind; And that ye put on the new man, which after God is created + (Collos., 3:8-10): But now ye also put off all these; anger, wrath, malice, blasphemy, filthy communication out of your mouth. Lie not one another, seeing that ye have put off the old man with his deeds; And have put on the new man, which is renewed in knowledge after the image of him that created him +

(Rom.,7:19): For the good that I would I do not: but the evil which I would not, that I do. +

\section{let compare:}

(1 John,1:8): If we say that we have no sin, we deceive ourselves, and the truth is no in us $\leftrightarrow$

(1 John, 3:9): Whosoever is born of God doth no commit sin].

- The Bible is the human book $\leftrightarrow$ God inspired book.

- The transcendence $\leftrightarrow$ the immanence of God.

- The human body: the mortality $\leftrightarrow$ the resurrection.

Incomprehension of these antinomies had brought and even now brings to the appearing of many heresies in the history of the Christianity.
By the way, let remind the words of Jesus Christ "Because strait is the gate, and narrow is the way, which leadeth unto life, and few there be that find it"(Matth.,7:14). This narrow way is between two extremities, figured in paradox, responds to the indestructible balance of the biblical doctrine.

In a certain degree the existence of two types of theology: apophatic (negative) and cataphatic (positive). Apophatism rises to God by the way of negation of all human representations of God because no one can present His majesty. Kataphatism characterizes the essence of God but cannot exhaust it: God reveals Himself to man as Love, Kindness, Wisdom,...- in the most complete way by Jesus Christ, in Whom was "all the fullness of te Godhead bodily" (Coloss., 2:9).

\section{Conclusion: Advantage of Paradox and Antinomy}

These and many other paradoxes can be explained (by the way, as also the Goedel theorem) by that, that man (although he was created by образу и подобию Бога) is limited and finite unlike to the infinite God, for Whom there are neither paradoxes, nor antinomies, moreover nor contradictions. From this statement it follows that although paradoxes and antinomies freely originate as the result of the creative thinking of the separate scientists, philosophers and theologians, they at the same time inevitable for the culture of the human thinking and therefore must be considered by thinkers with the necessary responsibility.

In conclusion one can notice that of course a truth can accept the paradoxical form but not any paradox is true.

True paradox (i.e. reflecting the reality) testimonies the versatility (polygonality) of truth - and it does not oppose to the human mind but in a certain sense is higher than mind. The Divine reveal exceeds the human understanding but in no way annihilates it! And namely the paradoxical formulations of the Christianity testimony on the versatility of truth.

Paradox opposes the self-confidence and the self-satisfaction of the human thinking, and its pride claims for the self-sufficiency. But it does not demand the annihilation of the human thinking. The human mind needs not the annihilation but the renewal (innovation) and only the renewed mind can cognize the Divine will (Rom.,12:2).

\section{References}

1. Ushinsky KD (1869) A man as the object of education, Progress Publishers, Moscow, USSR.

2. Olkhovsky VS (2003-2004) Course of logics in Kiev Christian University, Kiev, Ukraine.

3. Karpunin VA (2002) Logics and Bible, publisher "Bible for everybody”, Saint-Petersburg, Russia. 